\title{
On the changing seasonal cycles and trends of ozone at Mace Head, Ireland
}

\author{
D. C. Carslaw \\ Institute for Transport Studies, University of Leeds, Leeds LS2 9JT, UK \\ Received: 3 June 2005 - Published in Atmos. Chem. Phys. Discuss.: 15 August 2005 \\ Revised: 10 November 2005 - Accepted: 24 November 2005 - Published: 20 December 2005
}

\begin{abstract}
A seasonal-trend decomposition technique based on a locally-weighted regression smoothing (Loess) approach has been used to decompose monthly ozone concentrations at Mace Head (Ireland) into trend, seasonal and irregular components. The trend component shows a steady increase from 1990-2004, which is confirmed by statistical testing which shows that ozone concentrations at Mace Head have increased at the $\mathrm{p}=0.06$ level by $0.18 \pm 0.04 \mathrm{ppb} \mathrm{yr}^{-1}$. By considering different air mass origins using a trajectory analysis, it has been possible to separate air masses into "polluted" and "unpolluted" origins. The seasonal-trend decomposition technique confirms the different seasonal cycles of these air mass origins with unpolluted air mass maxima in April and polluted air mass maxima in July/August. A detailed consideration of the seasonal component reveals different behaviour depending on the air mass origin. For baseline unpolluted air arriving at Mace Head there has been a gradual increase in the seasonal amplitude, driven by a declining summertime component. The amplitude of the seasonal component of baseline air is controlled by a maximum in April and a minimum in July. For polluted air mass trajectories, there was a substantial reduction in the amplitude of the seasonal component from 1990-1997. However, post1997 results indicate that the seasonal amplitude in polluted air masses arriving at Mace Head is increasing. Furthermore, there has been a shift in the months controlling the size of the seasonal amplitude in polluted air from a maximum in May and minimum in January in 1990 to a maximum in April and a minimum in July by 2001. This finding suggests that there has been a steadily decreasing influence of polluted air masses arriving from Europe. These air masses have therefore increasingly taken on the attributes of baseline air.
\end{abstract}

Correspondence to: D. C. Carslaw

(d.c.carslaw@its.leeds.ac.uk)

\section{Introduction}

There is considerable interest in tropospheric ozone for many reasons. On a local to regional scale, photochemical ozone pollution remains an important health risk in many parts of the world. Additionally, ozone is damaging to agricultural crops, forests and materials. Ozone is also the third most important greenhouse gas and is the principal source of the hydroxyl radical (Houghton et al., 2001). The seasonal cycle of ozone in the troposphere is controlled by a wide range of chemical and dynamical processes (Scheel et al., 1997; Monks, 2000). One of the most distinctive characteristics of the ozone seasonal cycle in the Northern Hemisphere is the springtime maximum, which has been extensively investigated (Derwent et al., 1998b; Monks, 2000; Wang et al., 2003). Recently, global models and measurement campaigns have highlighted the extent to which ozone is a transcontinental problem. Li et al. (2002) using the GEOS-CHEM model found that North American anthropogenic emissions contribute 5 ppb ozone on average at Mace Head on the west coast of Ireland. Derwent et al. (2004) using the STOCHEM model suggest that about $12 \mathrm{ppb}$ ozone at Mace Head is North American in origin and about 7 ppb is Asian. In Europe there has been a reduction in ozone precursors leading to a reduction in peak summertime ozone concentrations (Derwent et al., 2003). Ozone concentrations have also been shown to increase as a result of biomass burning events (Honrath et al., 2004; Simmonds et al., 2005). At remote locations such as Mace Head, it has been observed that ozone concentrations are increasing in tropospheric baseline air masses (Simmonds et al., 2004).

Many of these influences would be expected to affect the seasonal cycle of ozone concentration in different ways. For example, the reduction in precursor emissions in Europe would be expected to reduce peak summertime ozone concentrations. Conversely, reduced concentrations of $\mathrm{NO}_{\mathrm{x}}$ in Europe would tend to result in less ozone titration through the

(C) 2005 Author(s). This work is licensed under a Creative Commons License. 
$\mathrm{O}_{3}+\mathrm{NO}$ reaction, particularly during the winter, thus leading to increased wintertime ozone concentrations. On the other hand, transport of ozone from North America tends to be most important during the spring and autumn, coinciding with periods of efficient ozone production, long ozone lifetime and fast transport (Wang et al., 1998; Li et al., 2002). These factors all potentially affect the ozone seasonal cycle in terms of the timing of peaks or troughs, the amplitude and the seasonal trend. For these reasons it can be useful to focus specifically on the seasonal aspects of ozone concentration as a method of recording and understanding the factors controlling ozone concentrations.

A large amount of work has been undertaken that considers the sources and sinks of ozone at Mace Head, Ireland (Derwent et al., 1998b, 2004; Salisbury et al., 2002; Simmonds et al., 2004, 2005). The unique location of Mace Head, which is often influenced by "background" air masses, makes it a good location in which to understand the factors affecting tropospheric ozone concentrations. Derwent et al. (2004) considered the seasonal cycles of ozone and other trace gases in detail at Mace Head for the period 1990 1994. It was shown that the springtime maxima and summertime minima in monthly mean ozone concentrations were also observed for other trace gases including: carbon dioxide, nitrous oxide, methane and methyl chloroform. Trends in ozone have also been calculated at Mace Head, which have highlighted that concentrations of ozone are increasing in baseline air (Derwent et al., 2003; Simmonds et al., 2004). Despite the considerable interest in surface ozone concentrations, very little work has been undertaken to determine whether the seasonal cycle of ozone is changing e.g. the timing of peaks or troughs in ozone concentration and how this might vary by air mass type.

There are many approaches available to extract the seasonal and trend components from time series. Traditional approaches decompose a time series into a long term component and an additive seasonal component and assume that seasons differ only in magnitude. The additive assumption if often inappropriate for air pollution data because seasonal effects can have a different forcing over time. Given the importance of the seasonal cycle to ozone concentrations, discerning systematic changes to the seasonal pattern is essential to developing an understanding of the processes controlling ozone concentrations and changes in concentration over time. For this reason a more flexible approach is required. Much of the motivation for time series decomposition derives from the analysis of economic data where information, such as unemployment rates, is expressed as seasonally adjusted (Franses, 1996). An extensively used empirical method, known as X-11, has been applied for several decades to produce official statistics by various governments and institutions. The method was introduced in 1965 by the U.S. Census Bureau and has undergone many developments (Shiskin et al., 1967). Latterly, the method has been developed to include Autoregressive Integrated Moving Average
(ARIMA) modelling to improve "end-effect" problems and extensive statistical diagnostic tools (Dagum, 1980; Findlay et al., 1998). Recently, the X-11 approach has been used to highlight the seasonal variability sea surface temperatures (Pezzulli et al., 2005). Model-based approaches have also been used to examine changes in ozone seasonality at Jungfraujoch in Switzerland, where a state-space method was applied (Schuepbach et al., 2001). The state-space approach showed that there had been a statistically significant negative trend in May ozone over a 10 year period, which was not statistically significant when ordinary linear regression was used.

In the current work, a seasonal-trend decomposition technique is used to extract the seasonal and trend components of ozone for different air mass origins at Mace Head, Ireland. A locally weighted regression (Loess) method of seasonal trend decomposition (STL) is used that provides a nonparametric means of describing nonlinear trends and seasonal cycles. STL was used in preference to X-11 because of the ease with which STL can be modified for specific applications. By employing methods that aim to extract different components of the ozone time series, attention can be focussed on different aspects of the ozone seasonal cycle and trends.

\section{Data and methods}

\subsection{Measurement data and site description}

Mace Head is situated at a coastal location on the west coast of Ireland $\left(53^{\circ} \mathrm{N}, 10^{\circ} \mathrm{W}\right.$; sampling height $25 \mathrm{~m}$ above sea level). The location of Mace Head is ideally suited for the analysis of different air mass origins. For the majority of the time Mace Head is influenced by air masses that have travelled across the North Atlantic with a fetch of several thousand kilometres. The analysis of trace gas data at Mace Head can therefore provide an insight into global background concentrations (e.g. Derwent et al., 1998a, b; Simmonds et al., 2004). Mace Head is also affected less frequently by more polluted air masses that derive from European sources. An important aspect of this location therefore is the potential to investigate tropospheric background air and air that has been strongly influenced by anthropogenic sources. Ozone measurements were made with a commercial Monitor Labs 8810 using a UV spectrometer (254 nm) (Derwent et al., 1998b). The instrument is calibrated every three months against a primary UV photometer and has a precision of $\pm 1 \mathrm{ppb}$ according to the manufacturer. Ozone measurements are recorded as hourly means, from which monthly means were calculated. The data set used covered a period from January 1990 to December 2004.

\subsection{Data filtering}

Ozone data at Mace Head have previously been filtered depending on air mass origin (Derwent et al., 1998b; Prinn et 
al., 2000; Simmonds et al., 2004). Simmonds et al. (2004) presented three techniques: pollution filtering based on the concentrations of different trace gases, trajectory analysis and the use of a Lagrangian model. The method adopted presently is filtering based on an analysis of EMEP (Cooperative programme for monitoring and evaluation of the long range transmission of air pollutants in Europe) back trajectories. With this method, back trajectories are followed for $96 \mathrm{~h}$ at a pressure height of $925 \mathrm{hPa}$. Four trajectories are calculated each day. The area around the arrival point is divided into 8 equal sectors of $45^{\circ}$. North $(\mathrm{N})$ is defined as being centred on $0^{\circ}$, north-east (NE) centred on $45^{\circ}$ etc. Days are allocated to a particular sector if at least $50 \%$ of the trajectory positions are found within that sector. If trajectories cannot be assigned in this way they are classified as unattributable. Derwent et al. (1998a) defined "unpolluted" or baseline air as deriving from N, NW, W and SW, which is also the assumption made here. Polluted air masses from Europe were assumed to derive from wind sectors NE, E, SE and S. Data were available from 1990-2001. Over the period 1990-2001, 54\% of conditions were classified as baseline, $14 \%$ polluted and $32 \%$ were unattributable. A disadvantage of the trajectory allocation approach is the large proportion of unattributable trajectories. However, these are considered further in Sect. 3.4, where the characteristics of these air masses are compared with baseline and polluted air masses.

\subsection{Seasonal-trend decomposition using Loess}

A time series can be considered to comprise three components: a trend component $T(m)$, a seasonal component $S(m)$ and a remainder $R(m)$,sometimes referred to as the irregular component:

$Y(m)=T(m)+S(m)+R(m)$

Where $Y(m)$ is the time series of interest.

The locally weighted regression smoothing technique (Loess) developed by Cleveland (1979) has been widely used in data analysis. The Loess technique has also been developed as a tool for seasonal-trend decomposition (STL seasonal-trend decomposition using Loess) (Cleveland et al., 1990). The STL method consists of a series of applications of a Loess smoother with different moving window widths chosen to extract different frequencies within a time series. The nonparametric nature of STL makes it suitable for dealing with non linear trends. Furthermore, the STL approach provides an effective graphical analysis of the different time series components, which is useful for diagnostic checking. The technique is also able to deal with missing data.

The STL method involves an iterative algorithm to progressively refine and improve estimates of the trend and seasonal components. STL consists of two recursive procedures, one nested within the other, called the inner loop and the outer loop. Each pass of the inner loop applies seasonal smoothing that updates the seasonal component, followed by trend smoothing that updates the trend component. An iteration of the outer loop consists of one or two iterations of the inner loop followed by an identification of extreme values. Further iterations of the inner loop down-weight the extreme values that were identified in the previous iteration of the outer loop. Typically, less than 10 iterations of the outer loop are carried out to ensure convergence. Because each month is a sub-series in the Loess fitted model, changes in the seasonal effects are captured. This attribute makes STL an effective tool for investigating seasonal ozone trends where there are likely to be different influences affecting the seasonal ozone cycle over time. The statistical robustness of the STL method is also a useful attribute when applied to concentrations of atmospheric species that are often influenced by events such as pollution episodes leading to outliers, which could adversely affect the clean extraction of an underlying trend or seasonal component.

There are several important parameter choices that must be made in STL. Many depend on the individual data sets being processed (e.g. whether daily or monthly data are used). Probably the most important choice is the value for the seasonal smoothing parameter, $n(s)$. As $n(s)$ increases, each cycle sub-series (e.g. the series of all January values in a monthly data set) become smoother. The choice of parameters should also ensure that the seasonal and trend components do not compete for the same variation in the data. Furthermore, parameters are chosen such that long-term oscillations are represented in the trend component and not the remainder. Cleveland et al. (1990) recommend a series of graphical diagnostic methods to determine the choice of parameters in STL, which have been followed in this study.

\section{Results and discussion}

\subsection{General description of the decomposed series}

Figure 1 shows the results of applying the technique to monthly ozone data from Mace Head. The figure shows that the trend component has been slowly increasing from 19902004, while also highlighting other long-term features. The peak in the trend component in 1998/1999 is likely to relate to biomass burning for example (Simmonds et al., 2004). The seasonal component shows a peak around April and a minimum around July each year. The amplitude of the seasonal component is also shown to increase at $0.27 \mathrm{ppb} \mathrm{yr}^{-1}$ throughout the time series. This increase is due to a small increase in springtime maxima of $0.04 \mathrm{ppb} \mathrm{yr}^{-1}$ and a decrease in the summertime minima of $0.23 \mathrm{ppb} \mathrm{yr}^{-1}$. The remainder component contains a proportion of data for each month that is not described by either the trend or seasonal components. The remainder component contains, for example, periods that might be affected by short-term air pollution episodes, such as are shown by the negative values in January 


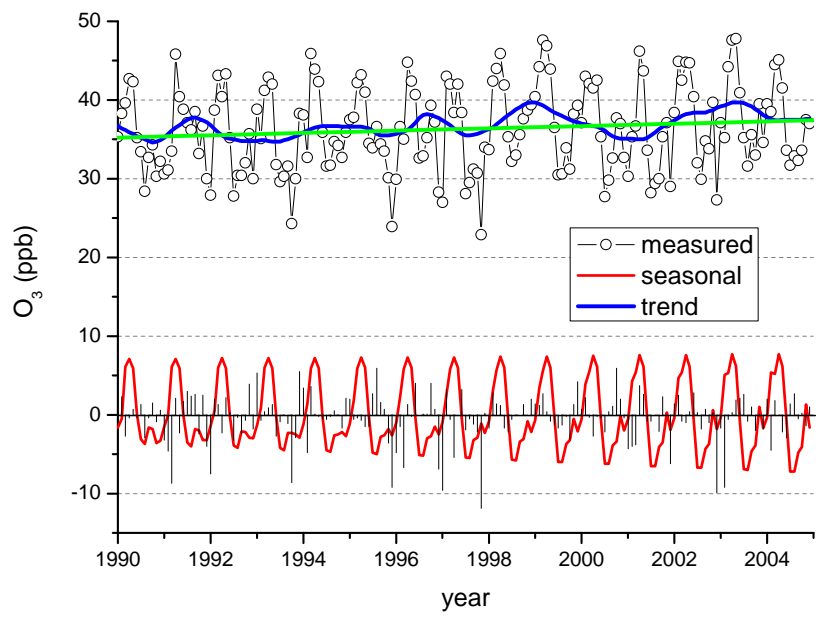

Fig. 1. Seasonal decomposition using STL applied to monthly ozone data measured at Mace Head (January 1990-December 2004). The circles show the original time series. The blue line is the trend component $T(m)$ the red line shows the seasonal component $S(m)$, and the remainder $R(m)$ are shown by the black bars. The green line shows the linear regression fit through the measurements.

and November 1997. An analysis of the components in Fig. 1 shows that most of the variance is in the seasonal component and the least in the trend. As the time scale reduces, for example, to a weekly time series, the variance in the remainder term increases to be approximately equal to that of the seasonal component. For monthly data therefore, the seasonal component is the most important characteristic controlling the variation in ozone concentrations.

Figure 2 shows the monthly variation in the seasonal components for different air mass origins averaged over 19902001. For baseline air trajectories, there is a clear peak in the seasonal component in March/April and a minimum in July/August. The polluted air mass trajectories peak later in April/May and have their minimum in December/January. The polluted minus baseline seasonal component has a very different variation, with a clear peak in July/August and a minimum in December/January. The latter plot appears to highlight summertime ozone production that would be expected in polluted air masses from Europe. These results also provide some evidence that the allocation into baseline and polluted air mass origins using the EMEP daily sector methodology adequately distinguishes between air masses with different characteristics.

\subsection{Trends}

The non-parametric seasonal Mann-Kendall analysis was applied to the measured monthly mean ozone concentrations from 1990-2004 to determine whether there was a significant change in the trend (Hirsch et al., 1982). These results showed that there has been a statistically significant upward

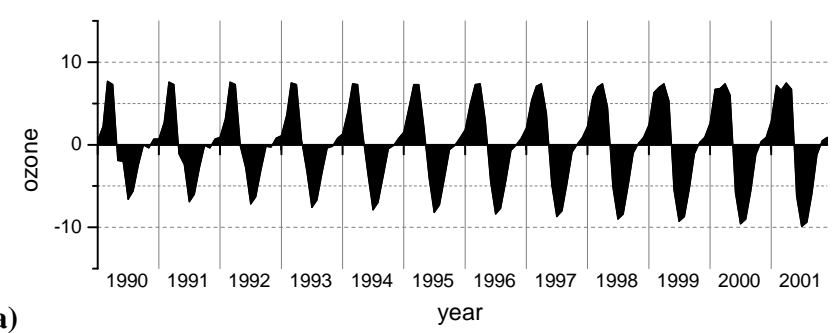

(a)

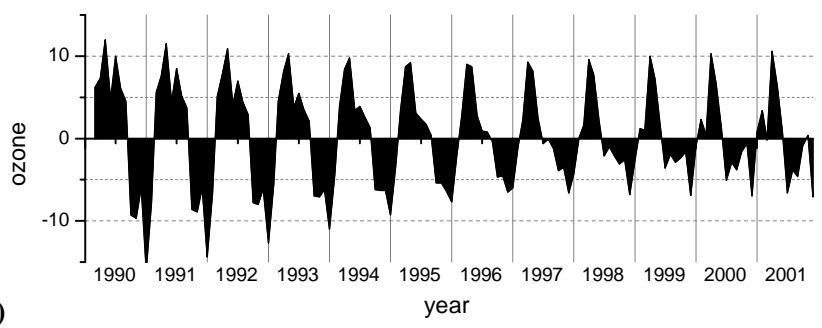

(b)

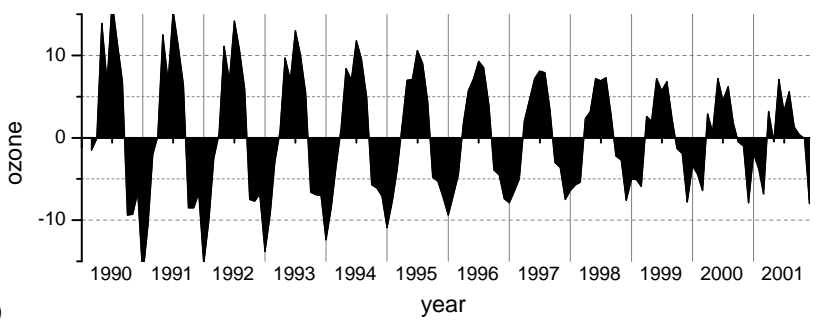

Fig. 2. Mean monthly variation in the ozone seasonal component for baseline, polluted and polluted minus baseline air mass trajectories. Data are for Mace Head from 1990-2001.

trend in ozone concentrations over this period at the $\mathrm{p}=0.06$ level. An analysis by linear regression of the extracted trend component suggests an increase of $0.18 \pm 0.04 \mathrm{ppb} \mathrm{yr}^{-1}$ (at a $95 \%$ confidence interval). The most significant increases $(\mathrm{p}<0.10)$ were observed for March-May and November. Non-significant decreases in ozone were calculated for July, August and September. Overall, increases in ozone for different months were more statistically significant than any decreases.

The slope of the extracted trend component for each of the time series by air mass origin was calculated using a linear regression. For baseline air a $0.25 \pm 0.06 \mathrm{ppb} \mathrm{yr}^{-1}$ increase in ozone was calculated from 1990-2001. For polluted air masses no change in the slope was calculated from 1990 $2001\left(0.01 \pm 0.10 \mathrm{ppb} \mathrm{yr}^{-1}\right)$. For air mass trajectories from a polluted direction it appears that increases in the baseline ozone over 12 years have been offset by decreases in ozone from polluted i.e. European air masses. The increase in baseline ozone of $0.25 \pm 0.06 \mathrm{ppbyr}^{-1}$ using the STL approach is in good agreement with that calculated by Simmonds et al. (2004) of $0.30 \pm 0.25 \mathrm{ppb} \mathrm{yr}^{-1}$ using the EMEP daily allocation technique, for data from April 1987 to March 2003. Although not shown, the slope of the trend in the unallocated air mass trajectories was $0.20 \pm 0.07 \mathrm{ppb} \mathrm{yr}^{-1}$, which is closer to the slope for baseline air than polluted air. 


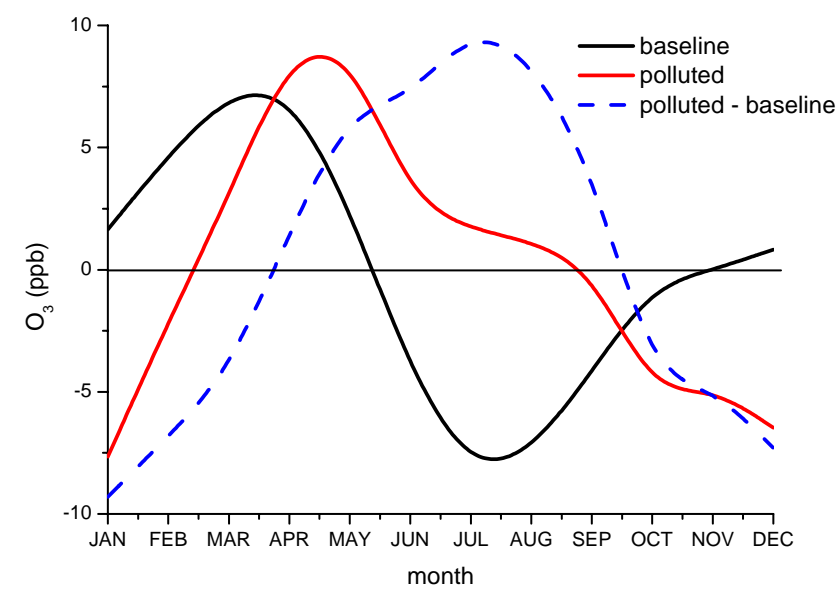

Fig. 3. (a) Seasonal cycle in Mace Head baseline air, (b) polluted air mass trajectories, (c) polluted air mass minus baseline air. Data are from 1990-2001.

Given that baseline air trajectories account for $54 \%$ of the air masses arriving at Mace Head and polluted 14\%, it seems reasonable to expect the unallocated trajectories to be dominated by baseline air. These slopes for the different air mass components (baseline, polluted and unallocated) are consistent with an overall trend of $0.18 \pm 0.04 \mathrm{ppb} \mathrm{yr}^{-1}$. The preferred pollution filtering technique used by Simmonds et al. (2004) did, however, yield greater rates of growth for both baseline and polluted air masses $\left(0.49 \pm 0.19 \mathrm{ppb} \mathrm{yr}^{-1}\right.$ and $0.40 \pm 0.32 \mathrm{ppb} \mathrm{yr}^{-1}$, respectively). In the context of the current work, these growth rates appear to be too high. The trend in ozone will, however, be sensitive to the time period considered. Simmonds et al. (2004) considered the period from April 1987 to March 2003 compared with January 1990 to December 2004 in the current work.

\subsection{Seasonal components and amplitudes}

Figures $3 \mathrm{a}-\mathrm{c}$ show the seasonal component extracted for three different air mass types using the STL technique. In Fig. 3a for baseline air arriving at Mace Head there is some evidence that the amplitude of the seasonal cycle is increasing. Furthermore, the ozone maximum in April each year broadens into February. The summertime minimum observed in baseline air at Mace Head is believed to partly explained by long-range transport from more southerly latitudes and the photochemical destruction of ozone in a low$\mathrm{NO}_{\mathrm{x}}$ environment (Scheel et al., 1997). For air masses from a polluted origin (Fig. 3b), the seasonal cycle is less smooth. There also appears to be a reduction in the amplitude of the seasonal component, caused primarily by an increasing wintertime ozone component. The peak in May remains approximately constant but there is some suggestion in Fig. 3b that this peak increases towards the end of the time series. Air masses from the polluted sectors also incorporate an impor-

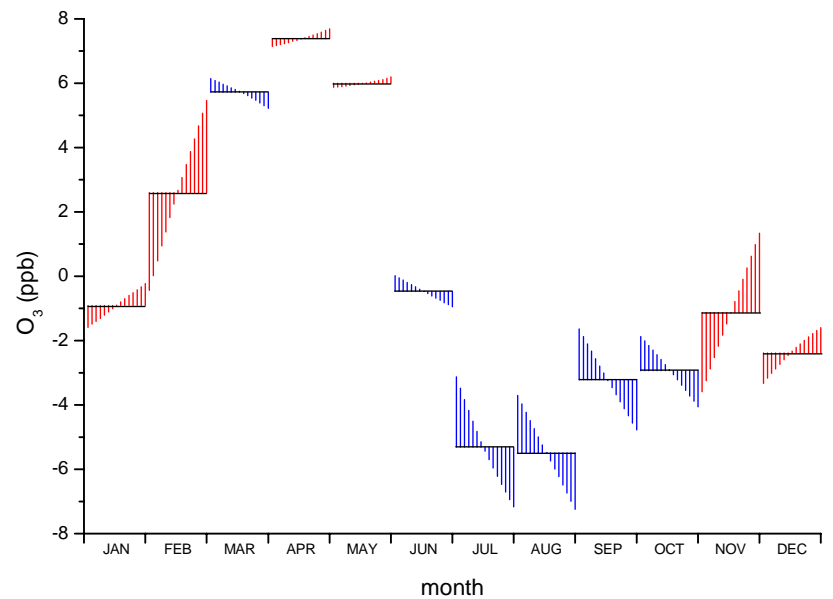

Fig. 4. Seasonal cycle sub-series plot for Mace Head ozone data (1990-2004). The red and blue lines show months where the seasonal component is increasing and decreasing, respectively.

tant contribution from baseline air. Therefore, the difference (polluted minus baseline) seasonal component is considered. Figure $3 \mathrm{c}$ shows this difference and highlights a clear reduction in the seasonal component amplitude from 1990-2001. The variations in these amplitudes and seasonal components are considered more in Sect. 3.4.

Even though the seasonal plots shown in Fig. 3 portray useful information, it is difficult to assess the behaviour of each cycle sub-series. A better interpretation of the seasonal component can be gained by plotting the cycle sub-series to highlight the characteristics of the seasonal component (Cleveland et al., 1990). Figure 4 shows the cycle sub-series of the monthly Mace Head data. First, the January values are plotted for successive years, then the February values, and so on. The individual values of a sub-series are shown as a series of vertical lines about the mean of the sub-series. The sub-series plot allows for an assessment of the magnitude of the seasonal component (as shown by the horizontal line for each month) and the behaviour of each monthly sub-series. Figure 4 shows for example, that April represents the month of the highest seasonal component and August the smallest. It also shows that the wintertime seasonal component is tending to increase, whereas for most summertime months there is a decrease with time. The increase in the seasonal component is most apparent for February and November. Conversely, the greatest decreases are most apparent in July and August. In addition, because all values shown in Fig. 4 are on the same scale, it is possible to determine whether the changes to any monthly sub-series are small or large compared with the month to month variation in the seasonal component. On this basis the changes shown for February and November appear to be large compared with the variation from month to month. 
Table 1. White noise $\sigma$ values by season for different air mass origins at Mace Head (ppb).

\begin{tabular}{lccccc}
\hline Season & All data & $\begin{array}{c}\text { Baseline } \\
\text { trajectories } \\
\text { Period }\end{array}$ & $\begin{array}{c}\text { Polluted } \\
\text { trajectories } \\
1990-2001\end{array}$ & $\begin{array}{c}\text { Baseline-Polluted } \\
\text { trajectories } \\
1990-2004\end{array}$ & $\begin{array}{c}\text { Unallocated } \\
\text { trajectories }\end{array}$ \\
\hline Winter (Jan., Feb., Dec.) & 4.1 & 2.6 & 6.9 & 6.9 & 4.2 \\
Spring (March, April, May) & 2.5 & 2.8 & 3.9 & 3.1 & 2.5 \\
Summer (June, July, Aug.) & 2.0 & 2.7 & 5.6 & 6.0 & 3.1 \\
Autumn (Sep., Oct., Nov.) & 2.9 & 3.0 & 4.7 & 5.0 & 3.4 \\
\hline
\end{tabular}

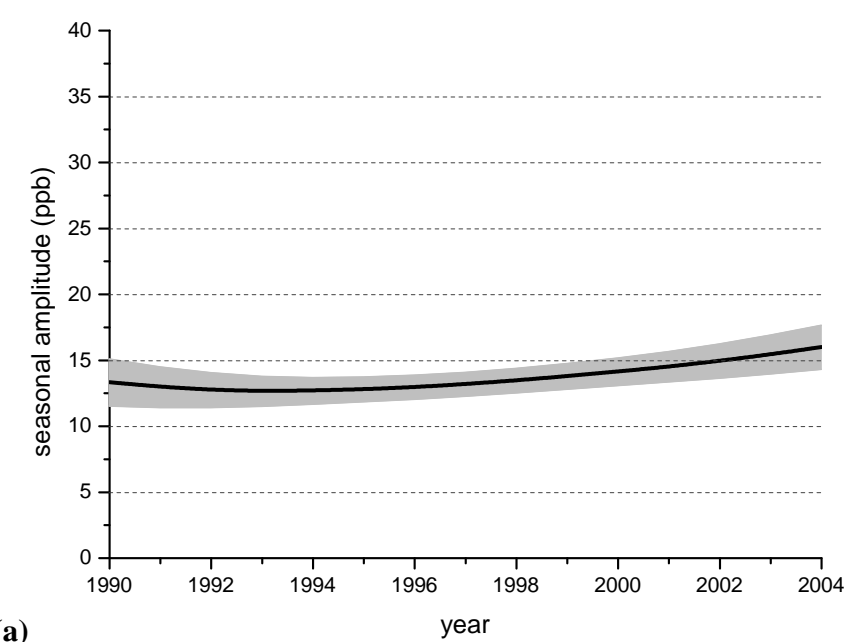

(a)

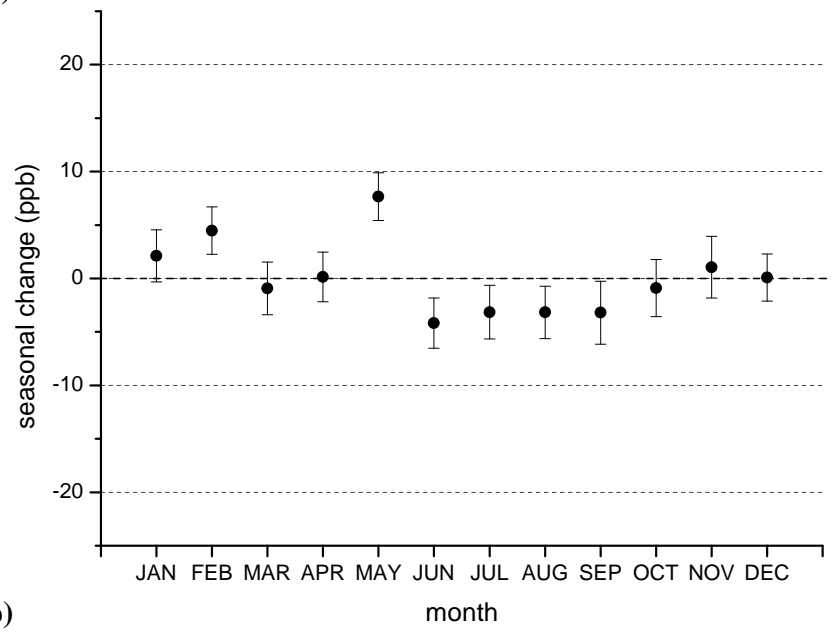

Fig. 5. (a) Trend in the amplitude of the seasonal ozone component $S(m)$ at Mace Head for all data 1990-2004, with the shading showing the error, (b) Seasonal change by month defined as the last monthly value in a time series minus the first monthly value for Mace Head ozone for all data 1990-2004. All errors shown are at $1 \sigma$.
3.4 Estimation of the uncertainties to changes in the seasonal component

Section 3.3 highlighted that the seasonal cycle of ozone at Mace Head has changed over the past 15 years, characterised by an increasing wintertime and decreasing summertime component. The changes shown for the seasonal ozone cycle are however subject to uncertainty. Monte Carlo simulations were carried out to estimate the errors in the change in the seasonal component as shown by Fig. 4 and changes in the amplitude in the seasonal cycle shown in Fig. 1. The remainder component $R(m)$, was used to describe the noise in the time series. An analysis of $R(m)$ in Fig. 1 by considering the correlegram showed that the series appeared to be random, with no obvious lag-effects. The $R(m)$ was also close to a normal distribution, with a mean close to zero. The $R(m)$ was however found to have a larger variance during winter and autumn months for each time series, probably as a result of wintertime pollution episodes. The higher uncertainty for polluted air masses compared with baseline air masses is in part due to the reduced occurrence of air mass trajectories arriving from the polluted sectors (see Sect. 2.2). Therefore, $\sigma^{2}$ was used to describe the seasonal variance of the residual term (shown in Table 1), and $\sigma^{2}(m)$ the time series of the residual term over the entire length of the data set. A large number of time series were constructed:

$Y(m)^{*}=T(m)+S(m)+W(m)^{*}$

where $T(m)$ and $S(m)$ are always the same series derived from the decomposition of the original series and $W(m)^{*}$ described as a Gaussian white noise series with a mean of zero and a variance $\sigma^{2}(m)$, derived from a Gaussian random number generator.

Simulations were undertaken to estimate the error terms in the seasonal amplitude and seasonal change as follows. First, a series of 500 synthetic ozone datasets were generated using Eq. (2) for 180 months of Mace Head ozone data shown in Fig. 1 (the length of the dataset). This process yielded 500 new time series, which were then decomposed using the STL method. This approach was also applied to the shorter time series (144 months) for the Mace Head baseline, polluted and unallocated air mass trajectories. For each of the 

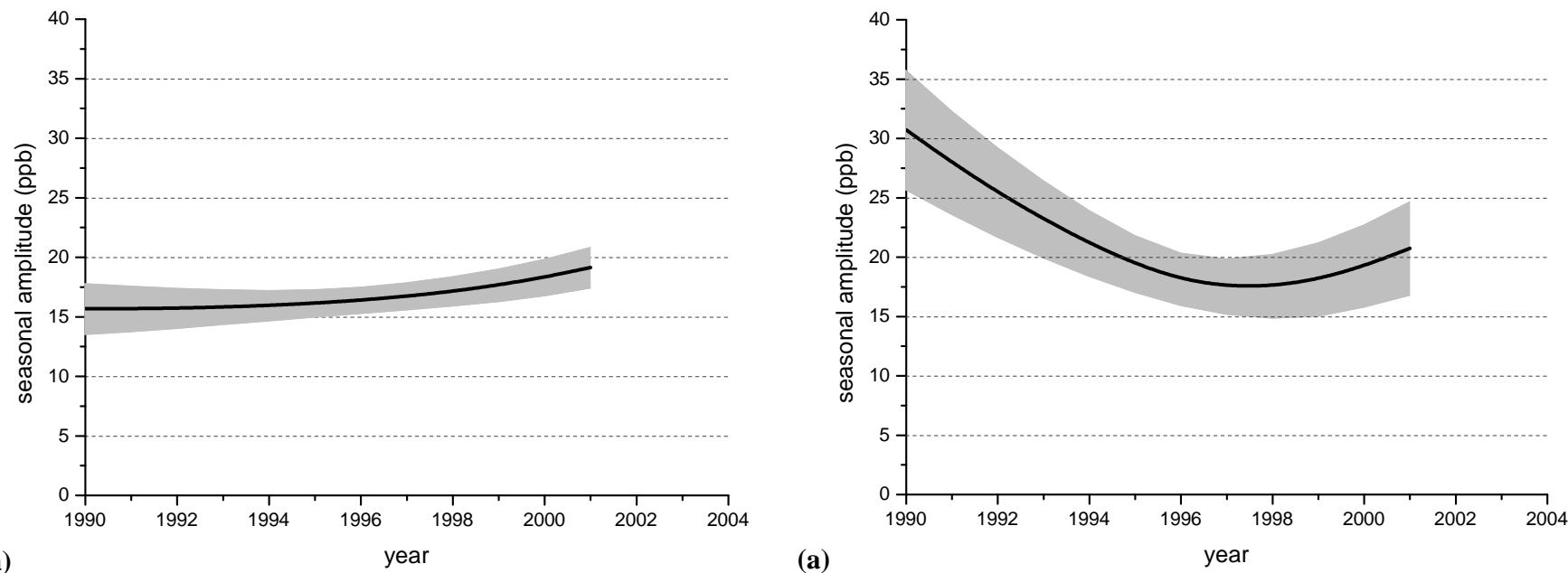

(a)

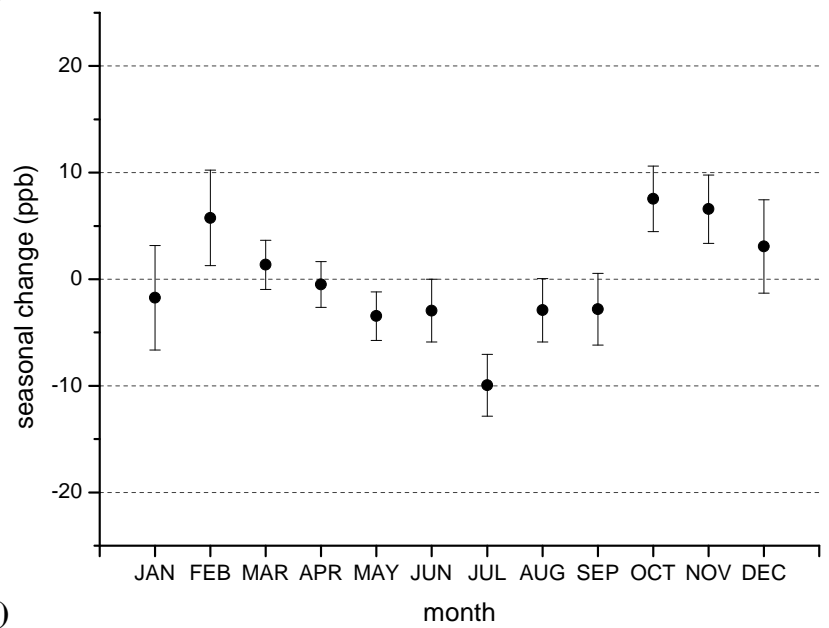

(a)

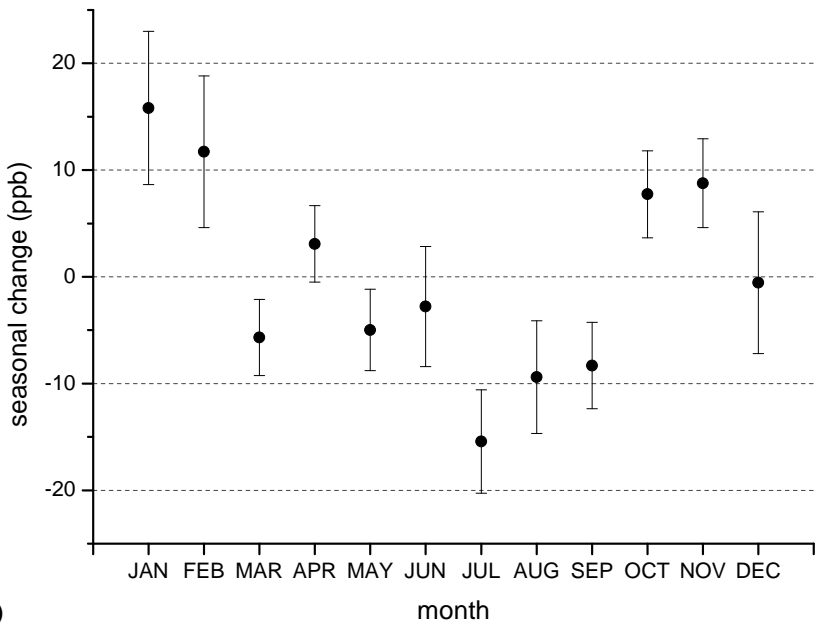

Fig. 6. (a) Trend in seasonal amplitude for filtered baseline trajectory data 1990-2001, with the shading showing the error, (b) trend in seasonal change by month for filtered baseline trajectory data 1990-2001. All errors shown are at $1 \sigma$.

new time series, the amplitudes of the seasonal component were calculated as the maximum $S(m)$ subtracted from the minimum $S(m)$ for each calendar year. The standard error of the amplitude for each year was calculated from the $500 \mathrm{am}$ plitude predictions. The change in the seasonal component was expressed as the last monthly value in each time series minus the first e.g. January 2004 minus January 1990 for the full Mace Head time series. The standard error associated with the seasonal change was also calculated.

Figure 5 shows the results for the changes in the seasonal amplitude and the seasonal change trend with associated errors for the different air mass types. Figure 5a shows that for the full Mace Head ozone dataset the seasonal amplitude increases with time. From 1990 to 1993 the amplitude decreases slightly (with a minima in 1993), but then shows a steady increase until 2004. Overall the increase in the seasonal amplitude is approximately 3 ppb ozone. The change

Fig. 7. (a) Trend in seasonal amplitude for filtered polluted trajectory data 1990-2001, with the shading showing the error, b) trend in seasonal change by month for filtered polluted trajectory data 1990-2001. All errors shown are at $1 \sigma$.

in the seasonal amplitude of about $3 \mathrm{ppb}$ is similar in magnitude to the uncertainty in the change, which suggests that the change is not highly statistically significant. The seasonal change trend is considered in Fig. $5 \mathrm{~b}$ and can be compared with Fig. 4, where changes in the monthly cycle sub-series are considered. For example, the comparatively large increases shown for February and November in the cycle subseries plot are also clearly shown in Fig. 5b. For the unfiltered data, increases in $S(m)$ are shown for most winter months and decreases in most summer months. The unfiltered data also show that the uncertainties are greater during the winter months compared with the summer months.

The trend in the seasonal amplitude shown for baseline air trajectories (Fig. 6a) also shows an increase in amplitude with time and no indication of a decrease from 1990-1993. The seasonal amplitude for the baseline air trajectories is also greater than the unfiltered data set. Figure $6 \mathrm{~b}$ for baseline 


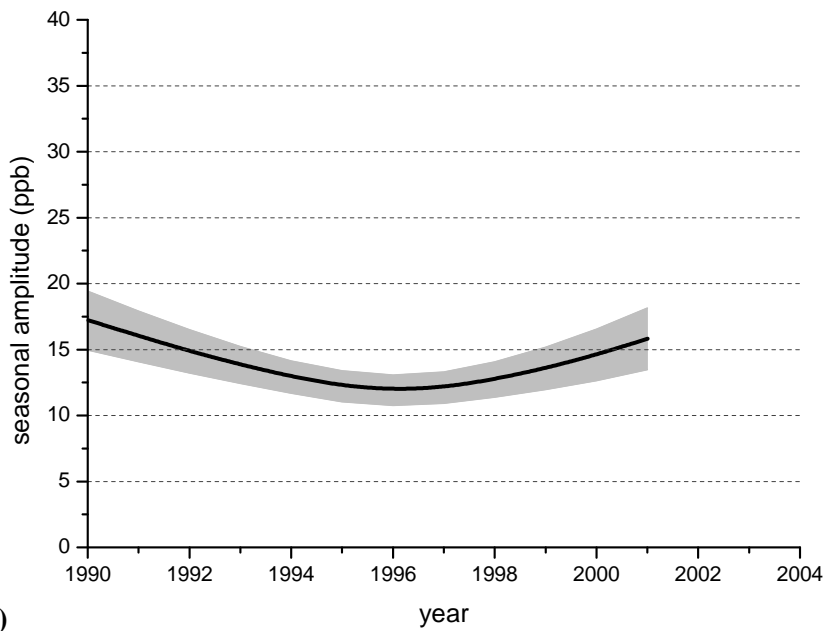

(a)

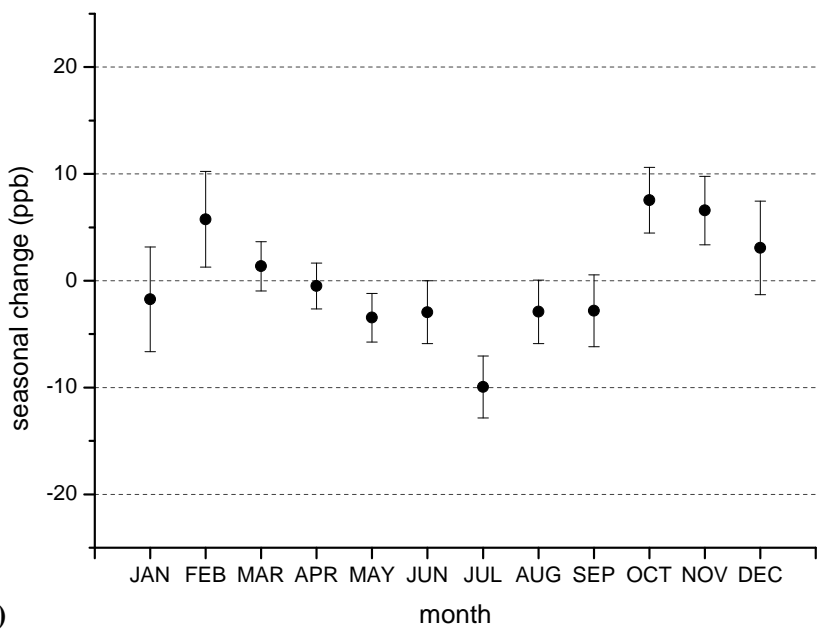

Fig. 8. (a) Trend in seasonal amplitude for unallocated trajectory data 1990-2001, with the shading showing the error, (b) trend in seasonal change by month for unallocated trajectory data 19902001. All errors shown are at $1 \sigma$.

air mass trajectories shows a similar pattern to the unfiltered data, although the increase in baseline May values appears to be anomalous. The uncertainties in the trend in seasonal change for baseline air are more uniform throughout the year compared with the unfiltered dataset, probably reflecting the reduced influence of summer or winter pollution episodes in baseline air.

Figure $7 \mathrm{a}$ shows that a very different trend is predicted for air mass trajectories from the polluted direction. At the beginning of the time series the amplitude of the seasonal component is approximately twice that for baseline air. This plot is characterised by a steep downward trend in the seasonal amplitude from 1990-1998, followed by an increase after 1998. This pattern of change reflects the diminishing influence of regional ozone through $\mathrm{NO}_{\mathrm{x}}$ and $\mathrm{VOC}$ controls in Europe through the 1990s, followed by the increasing importance of rising baseline ozone concentrations. The reduc- tion in the size of the May peak from 1990-2001 is driven by the reducing trend observed for all summer months. For the polluted air mass trajectories (Fig. 7b), increases are also apparent for most winter months and decreases during the summer months. The amplitude shown in Fig. 6a for baseline air is controlled by a maximum in April and a minimum in July each year. By contrast, the amplitude shown in Fig. 7a for polluted air masses is controlled by a maximum in May and a minimum in January at the beginning of the time series, and a maximum in April and a minimum in July at the end of the time series. The seasonal component of the polluted time series has therefore become increasingly like the baseline air component in terms of the months that control the size of the seasonal amplitude.

Also shown (Fig. 8a) is the trend in the seasonal amplitude for unallocated air masses. These air masses would be expected to comprise of air that is both baseline in origin and influenced by polluted European sources. The figure shows that the change in the amplitude with time does indeed reflect a combination of the increasing baseline amplitude and the decreasing amplitude for polluted air masses. The minima in amplitude occurs in 1996, i.e. 2 years before the polluted air masses. These results suggest that the baseline air begins to have a dominant influence on the unallocated air mass trajectories before that of the polluted air mass trajectories. This pattern of change is consistent with the increased influence of baseline air in the unallocated air mass trajectories and suggests that the unallocated trajectories are mostly influenced by baseline air characteristics. The trend in the seasonal component in Fig. 8b shows again an increasing wintertime trend and a decreasing summertime trend.

\section{Conclusions}

The seasonal trend decomposition technique (STL) applied to monthly ozone data at Mace Head has provided some insight into the factors controlling the seasonal ozone cycle and ozone trends. The application of the approach to different air mass origins from an analysis of trajectories has shown that there is a clear difference in the seasonal component of ozone. In baseline air masses, the seasonal component peaks in April and has a minimum in July, reflecting characteristic behaviour of northern hemisphere background air (Scheel et al., 1997; Monks, 2000). Conversely, it has been shown that the ozone seasonal cycle for polluted air mass trajectories arriving from Europe follow a pattern determined by photochemical ozone production which peaks in summer. The difference between these two air mass types suggests that the trajectory allocation of air masses into polluted and unpolluted categories is satisfactory.

By considering the amplitude of the extracted seasonal component it has been shown that baseline and polluted air masses have different characteristics. For baseline air from 1990-2001 there is a consistent maxima in April and minima 
in July each year, which define the seasonal amplitude, and is shown to increase over the length of the time series. This increase in amplitude is likely to be influenced by several factors, such as increasing ozone concentrations in air advected across the North Atlantic as a result of increasing $\mathrm{NO}_{\mathrm{x}}$ emissions in North America and Asia. Over the same period, polluted air masses arriving from Europe have shown a decreasing seasonal amplitude up to 1998, then increasing amplitude from 1998-2001. An interesting outcome from this analysis is that the seasonal component of polluted air masses arriving at Mace Head have changed markedly, such that by 2001 they show seasonal minima and maxima that are the same as baseline air. This finding suggests that there has been a steadily decreasing influence of polluted air masses arriving from Europe from 1990-2004. These air masses have increasingly taken on the attributes of baseline air. Monks et al. (2003) also highlight that as ozone precursor emissions are controlled, ozone measurements should increasingly reflect baseline air ozone characteristics. The current results highlights that these characteristics are already detectable at a remote location that is infrequently affected by polluted air masses from Europe.

Because there is no unique definition of seasonality, its characteristics depend on the method used to isolate the seasonal component. The focus in this study has been on the application of an empirical nonparametric approach. It would, however, be worth considering methods based on time series modelling to extract the different components. One such approach would be the application of autoregressive time series models based on ARIMA models. A potential advantage of such approaches is that they allow for statistical inference e.g. the estimation of the uncertainties in the extracted components. The applications of model-based approaches could potentially therefore provide a statistically more robust way of quantifying changes to the seasonal component.

An analysis of ozone data from other remote or rural monitoring sites in Europe using this technique has not been carried out but could also reveal the relative importance of different air masses on the seasonal ozone cycle. The approach offers an alternative method to commonly used techniques of trend detection, which might reveal more detailed information concerning changes to the seasonal and trend components of ozone concentrations. The decomposition approach also offers an alternative method of detecting large-scale atmospheric anomalies that affect northern hemisphere ozone concentrations over periods of several months. For example, the biomass burning ozone anomaly reported by Simmonds et al. (2005) during 1998/1999 measured at Mace Head is clearly detected in the extracted trend component.

Acknowledgements. Thanks are due to G. Broughton of AEA Technology plc for providing the 2004 Mace Head ozone data and to A.-G. Hjellbrekke of the Norwegian Institute for Air Research for providing the 2003 ozone data.

Edited by: N. Mihalopoulos

\section{References}

Cleveland, R. B., Cleveland, W. S., McRae, J. E., and Terpenning, I.: STL: A Seasonal-trend decomposition procedure based on Loess, J. Official Statistics, 6(1), 3-73, 1990.

Cleveland, W. S.: Robust Locally Weighted Regression And Smoothing Scatterplots, J. Am. Stat. Assoc., 74(368), 829-836, 1979.

Dagum, E. B.: The X11 Arima seasonal adjustment method, Statistics Canada, Catalogue 12-564E, 1980.

Derwent, R. G., Jenkin, M. E., Saunders, S. M., Pilling, M. J., Simmonds, P. G., Passant, N. R., Dollard, G. J., Dumitrean, P., and Kent, A.: Photochemical ozone formation in north west Europe and its control, Atmos. Environ., 37(14), 1983-1991, 2003.

Derwent, R. G., Simmonds, P. G., O’Doherty, S., and Ryall, D. B.: The impact of the Montreal Protocol on halocarbon concentrations in northern hemisphere baseline and European air masses at Mace Head, Ireland over a ten year period from 1987-1996, Atmos. Environ., 32(21), 3689-3702, 1998a.

Derwent, R. G., Simmonds, P. G., Seuring, S., and Dimmer, C.: Observation and interpretation of the seasonal cycles in the surface concentrations of ozone and carbon monoxide at Mace Head, Ireland from 1990 to 1994, Atmos. Environ., 32(2), 145-157, $1998 b$.

Derwent, R. G., Jenkin, M. E., Saunders, S. M., Pilling, M. J., Simmonds, P. G., Passant, N. R., Dollard, G. J., Dumitrean, P., and Kent, A.: Photochemical Ozone Formation in North West Europe and Its Control, Atmos. Environ., 37(14), 1983-1991, 2003.

Derwent, R. G., Stevenson, D. S., Collins, W. J., and Johnson, C. E.: Intercontinental transport and the origins of the ozone observed at surface sites in Europe, Atmos. Environ., 38(13), 1891-1901, 2004.

Findlay, D. F., Monsell, B. C., Bell, W. R., Otto, M. C., and Chen, S.: New capabilities and methods of the X12ARIMA seasonal adjustment program (with discussion), J. Business and Ecomomics Statistics, 16, 127-177, 1998.

Franses, P. H.: Periodicity and stocastic trends in economic time series, Oxford University Press, 1996.

Hirsch, R. M., Slack, J. R., and Smith, R. A.: Techniques Of Trend Analysis For Monthly Water-Quality Data, Water Resour. Res., 18(1), 107-121, 1982.

Honrath, R. E., Owen, R. C., Val Martin, M., Reid, J. S., Lapina, K., Fialho, P., Dziobak, M. P., Kleissl, J., and Westphal, D. L.: Regional and hemispheric impacts of anthropogenic and biomass burning emissions on summertime $\mathrm{CO}$ and $\mathrm{O}_{3}$ in the North Atlantic lower free troposphere, J. Geophys. Res.-Atmospheres, 109(D24), D24310, doi:10.1029/2004JD005, 2004.

Houghton, J. T., Ding, Y., Griggs, D. J., Noguer, M., van der Linden, P. J., Dai, X., Maskell, K., and Johnson, C. A.: Climate Change 2001: The Scientific Basis - Contribution of Working Group I to the Third Assessement Report of the Intergovernmental on Climate Change, New York, Cambridge University Press, 2001.

Li, Q. B., Jacob, D. J., Bey, I., Palmer, P. I., Duncan, B. N., Field, B. D., R. Martin, V., Fiore, A. M., Yantosca, R. M., Parrish, D. D., Simmonds, P. G., and S. Oltmans, J.: Transatlantic transport of pollution and its effects on surface ozone in Europe and North America, J. Geophys. Res.-Atmospheres, 107(D13), 4166, doi:10.1029/2001JD001422, 2002. 
Monks, P. S.: A review of the observations and origins of the spring ozone maximum, Atmos. Environ., 34(21), 3545-3561, 2000.

Monks, P., Richard, A., Dentener, F., Jonson, J., Lindskog, A., Roemer, M., Schuepbach, E., Friedli, T., and Solberg, S.: Tropospheric ozone and precursors, trends budgets and policy, TROTREP synthesis and integration report, http://atmos.chem. le.ac.uk/trotrep, 2003.

Pezzulli, S., Stephenson, D. B., and Hannachi, A.: The variability of seasonality, J. Climate, 18(1), 71-88, 2005.

Prinn, R. G., Weiss, R. F., Fraser, P. J., Simmonds, P. G., Cunnold, D. M., F. Alyea, N., O’Doherty, S., Salameh, P., Miller, B. R., Huang, J., Wang, R. H. J., Hartley, D. E., Harth, C., Steele, L. P., Sturrock, G., Midgley, P. M., and McCulloch, A.: A history of chemically and radiatively important gases in air deduced from ALE/GAGE/AGAGE, J. Geophys. Res.Atmospheres, 105(D14), 17 751-17 792, 2000.

Salisbury, G., Monks, P. S., Bauguitte, S., Bandy, B. J., and Penkett, S. A.: A Seasonal Comparison of the Ozone Photochemistry in Clean and Polluted Air Masses at Mace Head, Ireland, J. Atmos. Chem., 41(2), 163-187, 2002.

Scheel, H. E., Areskoug, H., Geiss, H., Gomiscek, B., Granby, K., Haszpra, L., Klasinc, L., Kley, D., Laurila, T., Lindskog, A., Roemer, M., Schmitt, R., Simmonds, P., Solberg, S., and Toupance, G.: On the spatial distribution and seasonal variation of lower-troposphere ozone over Europe, J. Atmos. Chem., 28(13), 11-28, 1997.
Schuepbach, E., Friedli, T. K., Zanis, P., Monks, P. S., and Penkett, S. A.: State space analysis of changing seasonal ozone cycles (1988-1997) at Jungfraujoch (3580 m above sea level) in Switzerland, J. Geophys. Res.-Atmospheres, 106(D17), $20413-$ 20 427, 2001.

Shiskin, J., Young, A. H., and Musgrave, J. C.: The X-11 variant of the census method II seasonal adjustment program, Technical paper 15, Washington D.C., Bureau of the Census, 1967.

Simmonds, P. G., Derwent, R. G., Manning, A. L., and Spain, G.: Significant growth in surface ozone at Mace Head, Ireland, 1987-2003, Atmos. Environ., 38(28), 4769-4778, 2004.

Simmonds, P. G., Manning, A. J., Derwent, R. G., Ciais, P., Ramonet, M., Kazan, V., and Ryall, D.: A burning question. Can recent growth rate anomalies in the greenhouse gases be attributed to large-scale biomass burning events?, Atmos. Environ., 39(14), 2513, 2005.

Wang, Y. H., Jacob, D. J., and Logan, J. A.: Global simulation of tropospheric O-3-NOx-hydrocarbon chemistry 3. Origin of tropospheric ozone and effects of nonmethane hydrocarbons, J. Geophys. Res.-Atmospheres, 103(D9), 10 757-10 767, 1998.

Wang, Y. H., Ridley, B., Fried, A., Cantrell, C., Davis, D., Chen, G., Snow, J., Heikes, B., Talbot, R., Dibb, J., Flocke, F., Weinheimer, A., Blake, N., Blake, D., Shetter, R., Lefer, B., Atlas, E., Coffey, M., Walega, J., and Wert, B.: Springtime photochemistry at northern mid and high latitudes, J. Geophys. Res.-Atmospheres, 108(D4), 8358, doi:10.1029/2002JD002227, 2003. 